\title{
A COMUNICAÇÃO NA EDUCAC̄̃̃ DE BEBÊS: QUANDO FALAR COM OS BEBÊS SIGNIFICA SINGULARIZAR PARA HUMANIZAR
}

\author{
Simone Silveira dos Santos ${ }^{1}$ \\ Suely Amaral Mello
}

RESUMO: Nascemos com uma única capacidade, a de aprender e, com isso, se desenvolver. Entretanto, precisamos estar em condições concretas favoráveis de vida e educação. A comunicação exercerá uma função essencial nesse processo. Neste texto objetivamos refletir sobre o papel da comunicação na educação da primeiríssima infância, a partir dos pressupostos teóricos da Teoria Histórico-Cultural, visando dialogar com os professores sobre a importância de falar com os bebês, de estabelecer uma relação e provocar neles novas necessidades, inclusive a de falar, levando ao desenvolvimento gradual de suas funções psíquicas (percepção, memória, atenção, linguagem) para que seja capaz de interpretar e compreender o mundo à sua volta de forma cada vez mais consciente e sofisticada. Com isso, busca-se como resultado contribuir para o avanço nas discussões da Pedagogia da Infância, bem como fornecer subsídios teóricos e metodológicos para uma prática pedagógica intencional, fundamentada e humanizadora.

PALAVRAS-CHAVE: Teoria Histórico-Cultural. Educação Infantil. Comunicação. Bebês.

\section{INTRODUÇÃO}

Nosso primeiro contato com o mundo se dá via os órgãos dos sentidos, desde a vida intrauterina, o meio exterior já nos provoca e mobiliza afetos. Após o nascimento, o outro exercerá um papel fundamental na apresentação e mediação entre o recém-chegado e a cultura produzida pela humanidade. A questão é, como se relacionar com um bebê? É preciso esperar um "tempo" para que seja capaz de compreender? Qual o papel do professor na primeiríssima infância? Tais questões são elementos cruciais para pensarmos o lugar que o bebê tem ocupado nas relações que estabelecemos com eles em nossas práticas educativas. Nós falamos com os bebês? Como e quando falamos com eles? E isto nos levará à questão central do texto: o bebê é sujeito ou objeto de nossa fala?

Por isso é fundamental nos questionarmos quanto ao lugar que a criança ocupa nas relações que participa, pois o desenvolvimento é um processo e não estanque. E isso implica pensar a forma também, pois impacta profundamente a formação humana. Pensando nas práticas pedagógicas desenvolvidas na Educação Infantil é preciso lançar algumas reflexões iniciais: Como organizamos tempo, espaço e conteúdos? A partir de que conceito de criança, infância, aprendizagem, ensino, desenvolvimento e educação? Para que projeto de sociedade?

1 Instituição: Universidade Estadual Paulista, Orcid: https://orcid.org/0000-0003-0152-9232,E-mail: simone-santos_lbv@hotmail.com 2 Instituição: Universidade Estadual Paulista, Orcid: https://orcid.org/0000-0002-2642-1669, E-mail: suepedro@terra.com.br 
Neste texto objetivamos refletir sobre o papel do professor no exercício de uma prática pedagógica intencional, fundamentada teoricamente, reconhecendo a fase da Educação da Infância, em especial a primeiríssima infância, com características próprias e fundamentais para o desenvolvimento rico e humanizador das características essencialmente humanas.

\section{EDUCAR E CUIDAR NA EDUCAÇÃO DA PRIMEIRA INFÂNCIA}

A história nos mostra que os direitos das crianças no Brasil datam do final do século XX. Sendo assim, a Educação Infantil tem sua trajetória anterior marcada pela ausência, omissão, exclusão ou reducionismo de sua função, ou seja, marcada ora pelo assistencialismo, ora compreendida como compensatória e higienista, ora compreendida apenas como fase preparatória para a escola e sempre dicotomizando o cuidar e o educar.

A virada para enxergá-la como um direito da criança somente se torna possível a partir da promulgação da Constituição de 1988 e, em seguida, do Estatuto da Criança e do Adolescente de 1990 que passam a concebê-la como prioridade absoluta. E isso irá se refletir nas políticas educacionais, na inclusão da Educação Infantil como uma etapa da Educação Básica na Lei de Diretrizes e Bases da educação nacional (LDB) de 1996, na elaboração das Diretrizes Curriculares Nacionais para a Educação Infantil de 2009, na emenda constitucional $\mathrm{n}^{\mathrm{o}} 59$ de 2009 que versa sobre a ampliação da obrigatoriedade de escolaridade que passa a ser dos 04 aos 17 anos de idade, assim como na lei $n^{\circ}$ 12.796/2013 que altera a LDB/96 e torna a matrícula na Educação Infantil obrigatória para crianças de 04 e 05 anos de idade e, mais recentemente, no Marco Regulatório da Primeira Infância (Lei n ${ }^{\circ} 13.257 / 2016$ ) que trata dos direitos e normatização das políticas públicas que priorizem o cuidado integral da criança de 0 a 06 anos de idade.

É importante demarcar que tais avanços legais são fruto da disputa de classes, das contradições da sociedade capitalista, entre as lutas da classe trabalhadora e as necessidades do capital. Entretanto, a realidade concreta mostra que, mesmo diante deste avanço, (ainda) para a classe trabalhadora esta é uma luta permanente, visto que a obrigatoriedade de oferta, por parte do Estado burguês, se dá a partir dos 4 anos e, de acordo com o IBGE, em 2018, cerca de um terço das crianças de 0 a 3 anos mais pobres do Brasil estavam fora da creche à espera de vaga. ${ }^{3} \mathrm{E}$ isto leva à um outro problema, que se consubstancia com as questões de classe, as questões de gênero, ou seja, a feminização da pobreza, pois, além de burguesa, a sociedade é patriarcal e, as mulheres ainda são pensadas como (quase que exclusivamente) responsáveis pelos cuidados com as crianças (e ao lar, sua eterna escravização) ${ }^{4}$ - o que as dificulta e/ou impede de trabalhar, de avançar em direção a melhores condições de vida.

Apesar da existência de tais avanços legais, é preciso materializá-los, ou seja, criar condições objetivas de existência para as crianças. E estas vão desde garantia de atendimento de suas necessidades básicas para a sobrevivência (melhores condições de vida para todos), até a criação de novas necessidades para o seu desenvolvimento rico e humanizador. E, nisto reside o papel da Educação Infantil.

$3 \mathrm{https} / /$ g1.globo.com/educacao/noticia/um-terco-das-criancas-de-0-a-3-anos-mais-pobres-do-brasil-estao-fora-da-creche-por-falta-de-vaga-diz-ibge.ghtml

4 Para maior aprofundamento ver as discussões promovidas pelas autoras Helena Hirata e Daniele Kergoat em "Gênero, patriarcado, trabalho e classe" e Silvia Federici em "Revolução ponto zero". 
Atualmente passamos pela implementação da Base Nacional Comum Curricular (BNCC), que vem sendo debatida, de forma intensa e polêmica, sendo redigida desde 2015, teve sua segunda versão aprovada em 2017 no que se refere ao campo da educação infantil. De caráter normativo, centro em aprendizagens essenciais que devem ser desenvolvidas e direitos de aprendizagens que devem ser garantidos, estruturado em cinco campos de experiências. Apesar de que, conforme apontam as autoras Lazaretti e Arrais (2018, p. 37), ter avançado no "a) reconhecimento da especificidade das dimensões do cuidado e das experiências no âmbito do desenvolvimento da criança; b) consideração dos interesses, das descobertas, das curiosidades da criança, concebendo-a como um sujeito ativo e participante do processo educativo", o documento não deixa claro quais elementos do patrimônio histórico e cultural da humanidade tem se privilegiado, além do risco de incorrer no negligenciamento do papel do professor em relação ao exarcebamento do protagonismo infantil. Contudo, neste artigo, não pretendemos aprofunda neste debate, entretanto, é preciso refletir no seu impacto na prática docente.

Não podemos perder de vista que a atuação docente na Educação Infantil foi por muito tempo, e ainda é, marcada pelo que Lima (2005, p. 86) denomina de "Pedagogia da Espera", pois ao conceber a criança como um ser passivo e que deva estar pronto para tal e tal aprendizado, "a criança espera porque não é capaz, espera para começar alguma tarefa porque não tem iniciativa. E o que é mais profundo, tais vivências cultivam nas crianças a atitude de dependência em relação ao adulto, a sua falta de iniciativa e de autonomia, o seu papel como espectadora." Ora passividade, ora espontaneismo. Tais práticas corroboram com as expectativas de passividade, docilidade e alienação da máquina de moer gente do capitalismo.

Uma prática revolucionária atua justamente no movimento oposto, ou seja, concebe a criança como capaz e investe na promoção de atividades propulsoras da sua conduta ativa, mobilizando capacidades psíquicas, reorganizando "o funcionamento cerebral tanto no que se relaciona às conexões neurais quanto ao movimento e à ativação dos processos psicológicos". (LIMA, 2005, p. 87) E para isso é fundamental conhecer as regularidades do desenvolvimento na infância e isso também significa uma nova concepção de professor, não apenas como alguém que reproduz práticas, que aplica atividades, que "dá aulas". Nos referimos aqui a uma concepção de professor como intelectual de sua prática (GRAMSCI, 2004), que conhece, fundamenta e intencionaliza uma educação promotora do máximo desenvolvimento humano.

Reflitamos sobre as práticas cristalizadas na educação de bebês, ou seja, a naturalização do bebê como incapaz, passivo, cuja prioridade prática envolve cuidar para não se machucar, e devolver alimentado e devidamente higienizado para responder às expectativas da família. Por muito tempo, acreditou-se que este era o papel do professor nesta fase da vida. Por outro lado, quando existem propostas que vão para além,

[...] se repetem: as mesmas músicas, os mesmos objetos, os mesmos brinquedos. De um modo geral, os bebês são deixados sem orientação num espaço de oferta de materiais para exploração; não há o estabelecimento de diálogos entre bebês-adultos; as intervenções dos adultos se resumem à solução de conflitos. (SILVA, 2018, p. 26)

Tais práticas precisam ser superadas, pois partem de uma concepção biologizante e determinista de desenvolvimento, quando já se demonstrou que é justamente porque aprende 
que a criança se desenvolve (VIGOTSKI, 2012). Entretanto, ainda que a criança se relacione com o mundo ao redor e aprenda por meio da atividade, não é toda atividade que promove o desenvolvimento de novas funções psíquicas. Leontiev (2001) pontua que há atividades que guiam o desenvolvimento em cada período da nossa vida.

A necessária revisão da concepção passiva que se tem do sujeito em relação ao desenvolvimento, sustentada também pela Teoria Histórico-Cultural, requer que os professores compreendam o processo pelo qual as atividades-guias promovem o desenvolvimento de novas formações psíquicas. Esta é uma condição para organizar intencionalmente a prática docente para proporcionar atividades - promotoras de desenvolvimento. Para isso, é essencial avançar na concepção de que o bebê, desde a mais tenra idade, atribui valor às experiências que vivencia - em outras palavras, aprende.

\section{O BEBÊ E O PROFESSOR COMO SUJEITOS ATIVOS E O PAPEL DA COMUNICAÇÃO}

Para iniciar nossa reflexão, consideramos a curta história que tem a pesquisa sobre as crianças pequenas educadas em creches, sobre como formam sua inteligência e personalidade e com isso, como planejar intencionalmente atividades que melhor promovam o desenvolvimento de suas funções psíquicas superiores. Contudo, para isso precisamos, além de conhecer as regularidades do desenvolvimento infantil, conhecer cada criança individualmente e isso requer comunicação e escuta. Mas, vamos iniciar focando o desenvolvimento.

Ao nascer, o bebê não se diferencia do meio, e a percepção será a primeira função psíquica a se desenvolver ligada às suas emoções, para as quais a sensação desempenha um papel central. Neste período da vida, o bebê enfrenta uma contradição, conforme apontada por Vigotski (2012): sua incapacidade biológica (depende do adulto para sobreviver), e, portanto, sua máxima socialibidade, ao mesmo tempo que mínima possibilidades de comunicação (carece de comunicação na forma de linguagem humana, se comunica de forma silenciosa, sem palavras, por olhares, gestos e sons que precisam ser compreendidos pelos adultos). Desde muito cedo, o bebê já começa a manifestar interesse à estímulos sensoriais, movimentos, sons e em pessoas. Até o primeiro ano de vida, o que une as funções sensoriais e motoras é o afeto. E conforme o próprio Vigotski (1996) anuncia, o ato de amamentar, supre uma necessidade biológica, mas cria outra necessidade, uma social, a de estar entre pessoas, de desejar ser acalentado no colo. E tudo isso demonstra que o bebê aprende desde que nasce.

A partir do que aprendemos com Vigotski (2012) e Leontiev (1978), na perspectiva da Teoria Histórico-Cultural, o desenvolvimento infantil passa por saltos qualitativos sob a influência de atividades que são essenciais, ou seja, que mais influenciam o desenvolvimento psíquico em cada etapa da vida, elas são denominadas de atividades-guia ou principal, a depender das condições de vida e de educação.

A primeira atividade-guia é a comunicação emocional direta, ou seja, o bebê vive uma intensa contradição no início da vida, sua máxima sociabilidade e a pouca capacidade biológica, pois depende dos adultos inteiramente para sobreviver, e suas mínimas possibilidades de comunicação. (VIGOTSKI, 2012)

É de fundamental importância o papel do adulto para o desenvolvimento do bebê, pois, o interesse positivo da criança por ele surge da interação, da afetação, ou seja, da forma como o adulto irá se relacionar com ela. Por isso, é preciso que nos coloquemos a seguinte reflexão: 
qual o lugar que a criança tem ocupado nas relações de que participa? De que forma se dão essas relações? De que forma temos apresentado o mundo da cultura para ela? Enquanto professores, como temos planejado e organizado o tempo e o espaço dos bebês visando enriquecer seu desenvolvimento? O quanto deste planejamento envolve a singularização e o desenvolvimento da autonomia e segurança emocional deles? A comunicação tem se colocado como um elemento chave?

Por muito tempo acreditou-se que a forma como são conduzidas as experiências vividas pelos bebês não tinha importância, uma vez que se acreditava ser necessário que a crianças estivessem apta para tal aprendizado, o que só aconteceria depois de certa idade. Por isso, nossa atenção não se centrava em discutir a relação hoje percebida como indissociável entre cognição e afeto, cuidar e educar, muito menos a postura docente, suas atitudes centralizadoras e autoritárias. Tais discussões começam a ganhar corpo a medida em que vamos aprendendo mais sobre o desenvolvimento infantil e estudando especificamente a educação na primeira infância e suas implicações.

A Teoria Histórico-Cultural nos convida a ver o bebê como sujeito ativo e capaz, que aprende desde que nasce e que, por isso, se desenvolve. Em lugar de olhar apenas para aquilo que o bebê ainda não é capaz de fazer, percebermos, a partir de um olhar atento, o que já é capaz de comunicar por meio de seu olhar, gesto, movimento, expressões, vocalizações, o que observa, pega, leva à boca, etc.

O bebê sente o mundo e se comunica por meio de seu corpo; suas sensações confundem percepção com emoção. Por isso é tão importante a forma como a pessoa adulta toca o bebê, como anuncia ao bebê sua presença e a sua intenção antes de tocá-lo, de tirá-lo do berço ou do chão, de trocá-lo de ambiente, de interromper aquilo que ele está fazendo. Mesmo o bebê não entendendo exatamente o que a pessoa adulta fala, sabe que algo vai acontecer com ele e se prepara para isso. (MELLO, 2017b, p. 32)

Por isso, é de fundamental importância que nossa atenção volte-se para o bebê visando intencionalmente uma relação, um envolvimento. Isso implica falar com ele, anunciar o que será feito (sem exageros no tom e na forma de falar), respeitar seu corpo ao tocá-lo (sem movimentos bruscos ou ríspidos). São justamente nos atos de cuidados (banho, troca, alimentação, sono) que vamos desenvolvendo o processo de educação, levando a criança a conhecer o próprio corpo, transmitindo segurança afetiva para que se sinta segura e confiante em ficar só enquanto o adulto pode dar atenção individual para outra criança. É o exercício do duplo protagonismo, da criança e do adulto. Para que seja efetivo este protagonismo, o professor precisa conhecer com profundidade os fundamentos do seu trabalho, ou seja: adotar uma concepção de criança, infância, desenvolvimento, aprendizagem, etc. com base em uma teoria desenvolvente (DAVYDOV, 1988), assumindo-se como um intelectual que planeja e estuda para desenvolver uma prática intencional e fundamentada.

Então, a partir da ação conjunta entre nós e o bebê, conforme vamos compreendendo suas necessidades imediatas e agindo sobre elas, vamos também possibilitando a ampliação de seu universo. Esta é como a primeira forma de escuta (MELLO, 2017c).

Lísina (1987, p. 276) define comunicação como uma "determinada interação de pessoas, no curso da qual intercambiam diferentes informações com o objetivo de estabelecer relações ou unir esforços para lograr um resultado comum". Para que a atividade comunicativa 
aconteça, é necessário, além da existência de dois sujeitos, que ambos se percebam envolvidos e distintos para desempenhar o papel que lhes cabem. Pensando assim, é fundamental destacar que a fala só se transforma em relação, só se torna comunicação, quando enxergamos o outro - neste caso, o bebê, e atendemos suas necessidades - isto como uma primeira etapa, pois é preciso ampliar seus afetos criando novas necessidades.

Volóchinov (2018) concebe a linguagem como fundamentalmente dialógica, o que significa que cabe ao outro uma atitude responsiva. Sendo a linguagem um fenômeno da interação verbal, esta se dá nas trocas ativas e dinâmicas entre os sujeitos que são produtores de enunciados. Nesse sentido, além de ser fundamental conceber as crianças (desde os bebês) como sujeitos, também é preciso construir com elas um processo dialógico. Isto pressupõe trabalho colaborativo e não prescritivo.

Na experiência conhecida como Lóczy ou abordagem Pikler (desenvolvida pelo instituto Emmi Pickler, em Budapeste - Hungria), exercita-se o que podemos denominar de Pedagogia da Escuta, ou seja, uma escuta intencional, por isso atenta e sensível, para identificar a situação social de desenvolvimento das crianças a partir do que os bebês estão dizendo em seus gestos, olhares, interesses, atitudes. Isso muda a atitude do adulto em relação ao bebê, pois a comunicação se torna elemento de fato mediador: os adultos falam com os bebês em todos os momentos, ou seja, na oferta de objetos, no banho, nas trocas, na alimentação. Essa comunicação estabelece uma relação de segurança e que é capaz de criar necessidades de comunicação nos bebês, quando "a palavra ganha forma orientadora da conduta da criança". (SILVA, 2018, p. 44)

A primeira forma de comunicação do bebê é definida por Lísina (1987) como situacional-pessoal e adquire sua forma desenvolvida no "complexo de animação" que são reações do bebê para com o adulto: concentração do olhar no adulto, sorriso, gestos, expressões, vocalizações e excitações motoras.

[...] Os componentes do complexo de animação servem de base para que o bebê comece a diferenciar no meio circundante a pessoa adulta (concentração), realizar a comunicação mímica (sorriso) e especificamente vocal (vocalizações pré-linguísticas) com o adulto e atrai-lo ativamente para a comunicação (excitação motora). (LÍsINA, 1987, p. 288)

Outro elemento principal neste processo é a atividade antecipadora do adulto, ou seja, o processo em que o mundo é apresentado ao bebê pelo adulto, induzindo, compartilhando, promovendo as condições para que o bebê vá se percebendo com um ser distinto. "A percepção diferenciada de objetos e indivíduos presentes numa situação é uma conquista na formação cultural do bebê". (CHEROGLU, MAGALHÃES, 2016, p. 103)

Desta forma a atividade de comunicação emocional direta encontra-se na base e orienta a ação com a produção de novos comportamentos infantis, na produção de novas necessidades, fazendo avançar o desenvolvimento.

É por meio dessa comunicação emocional que é sua forma essencial de relação com o mundo, que o bebê começa a se apropriar da fala e vai estabelecendo os primeiros contatos com o mundo. Essa comunicação, do ponto de vista da ação do adulto, envolve a fala da professora, o tom de voz e a fala que dirige ao bebê e espera uma manifestação dele; o modo como ela toca o bebê; o modo como se aproxima do bebê e anuncia que vai limpar seu nariz; o modo como anuncia o momento do banho, 
como o retira do berço e o leva para o banho; o modo como a professora anuncia o momento da alimentação e a relação que se estabelece enquanto o alimenta; o modo como organiza o espaço em que o bebê permanece enquanto está acordado. (MELLO, 2017a, p. 28)

Conforme o professor (ou adulto cuidador) estabelece uma relação afetivo-comunicativa com o bebê, apresentando o mundo da cultura, o mesmo vai sendo afetado pelas pessoas e objetos do seu entorno, passando assim a manipular objetos, emitir sons, sorrir, chorar, observar. E isso cria a demanda para a próxima atividade-guia, que é a objetal manipulatória, quando a atividade da criança está circunscrita à situação concreta, ou seja, tudo que está ao alcance de sua percepção vira objeto de sua atenção.

A figura do adulto perde a centralidade que tinha na etapa anterior, contudo, isso não significa que sua atuação não seja importante, pois, este adulto passa a figurar no papel de mediador entre a criança e o mundo dos objetos. É ele quem apresenta o mundo da cultura. Por isso o lugar da criança é no chão, mas não de qualquer jeito ou qualquer lugar e com qualquer coisa. Mas com objetos organizados que criem o desejo de explorá-los.

Nesta etapa da vida, a forma de comunicação do bebê avança para o que Lísinia (1987) define como comunicação prático-situacional. Aqui, os objetos é que irão mediar o processo.

\begin{abstract}
Os meios expressivo-mímicos conservam seu significado durante a comunicação. Inclusive se fazem mais ricos e variados: aparecem olhares, sorrisos de diversos matizes, a mímica vai se diferenciando e precisando. [...] Aparece toda uma categoria de novos meios de comunicação em forma de locomoções e atividades de objeto transformadas. (ZAPOROZET; LÍSINA, 1986, p. 163, tradução nossa)
\end{abstract}

A comunicação emocional não deixa de existir, ela se aprofunda. Vai se dando de forma individualizada e vai caminhando para a apropriação da fala. "O foco da fala será o conjunto de objetos que trazemos para enriquecer cada vez mais o entorno das crianças". (MELLO, 2017c, p. 75) O processo vivido pelo bebê ao longo dos dois primeiros anos de vida levará a uma nova e importante formação psíquica, o entrecruzamento da linguagem com o pensamento. As palavras passarão a orientar as ações das crianças com os objetos.

À medida que a linguagem e o pensamento se entrecruzam, uma nova e revolucio-
nária etapa se inicia no desenvolvimento infantil, pois esta é uma neoformação que
requalifica toda a interfuncionalidade psíquica. Ao trazer para a criança não só um
som pareado com uma representação, mas também o conceito, o significado, a pa-
lavra demanda generalização, e esta é uma tarefa do pensamento. (MAGALHÃES,
2018, p. 281)

Com a linguagem exercitada na relação, em colaboração com os adultos, o ato de comunicação origina a generalização e, com isso, a criança vai se tornando capaz de falar de objetos que estão ausentes, não fica mais dependente da situação concreta. Nesse processo, a linguagem vai se intelectualizando.

Isso nos remete à responsabilidade que nós professores (adultos) temos na formação da inteligência e personalidade das crianças, e, para isso, é fundamental que a prática pedagógica seja carregada de intencionalidade e conhecimento sobre as regularidades do desenvolvimento infantil, sobre a situação social de desenvolvimento em que se encontra a criança, ou seja, é fundamental conhecer o seu sistema de relações e a melhor forma como se comunica com 
a realidade, bem como a relação comunicativa que se estabelece. Nesse sentido, as vivências terão um papel crucial e isso implica pensar a forma como organizamos o ambiente para estimular a manipulação de objetos e nossas iniciativas de provocar a apropriação da fala pelas crianças. Esta é a segunda forma de escuta (MELLO, 2017c).

Vigotski (2018) aponta que a vivência tem um papel crucial no desenvolvimento humano, ou seja, o modo como o sujeito interpreta determinado fenômeno é o que condiciona o desenvolvimento. Vigotski caracteriza vivência "como unidade de elementos do meio e de elementos da personalidade, como unidade do subjetivo e do objetivo, como a unidade sujeito/cultura." (Mello, 2010, p. 729). Nas palavras do autor, a "vivência é uma unidade na qual se representa, de modo indivisível, por um lado, o meio, o que se vivencia - a vivência está sempre relacionada a algo que está fora da pessoa -, e, por outro lado, como eu vivencio isso." (VIGOTSKI, 2018, p. 78)

O meio é fonte do desenvolvimento das características especificamente humanas da criança. Destaca-se, portanto, ao lado do protagonismo infantil na relação com o meio, também o papel protagonista da cultura na formação e desenvolvimento das qualidades humanas.

\begin{abstract}
A maior particularidade do desenvolvimento infantil consiste no fato de que ele se realiza em condições de relação recíproca com o meio, quando a forma ideal, terminal, a que deve surgir ao final do desenvolvimento, não somente existe no meio contíguo à criança desde o início, como realmente interage e exerce in $\square$ uência sobre a forma primária, sobre os primeiros passos do desenvolvimento infantil, ou seja, sobre algo que deve se formar ao final e, de algum modo, in $\square$ uencia os primeiros passos do desenvolvimento. (VIGOTSKI, 2018, p. 85)
\end{abstract}

Quando a forma final ideal não está presente no meio, o desenvolvimento ocorre de forma lenta e limitada. Pensemos nos atos de fala dos adultos com as crianças. Se nos dirigimos a elas apenas para dar ordens e repreensões, as crianças além de sentirem medo, não criam novos interesses e isso poderá levar ao embotamento da vontade, da iniciativa, da autoestima. Outro problema é quando falamos com elas de forma "infantilizada", pois além de dificultar a compreensão (uma palavra no diminutivo é mais complexa), dificultamos o seu processo de apropriação da fala (uma vez que a criança imita o adulto e, se o adulto imitar a criança, a criança não avança no domínio da fala). Ambas as situações, além de empobrecedoras, têm por princípio uma dupla negação, da criança como sujeito ativo do seu processo de aprendizagem e do professor como sujeito ativo do seu processo de ensino.

Isto nos leva à "Lei genética geral" formulada por Vigotski (2018). Sendo o homem um ser social, as qualidades humanas se formam na interação com a sociedade, "as funções psicológicas superiores, as características superiores específicas do homem, surgem inicialmente como formas de comportamento coletivo da criança, como formas de colaboração com outras pessoas. Somente depois elas se tornam funções internas individuais da criança" (VIGOTSKI, 2018, p. 91). Ou seja, primeiro aparecem nas relações sociais, para depois se manifestarem como apropriações do indivíduo, como funções psicológicas superiores.

Refletir sobre os atos de fala de nós professores (adultos) com as crianças, bem como a importância da intencionalidade da fala, enquanto comunicação, implica investir numa relação entre sujeitos ativos, para fazer avançar e desenvolver a comunicação oral dos pequenos. Nós nos comunicamos de fato com elas? Ou apenas damos ordens e repreensões? Qual o 
lugar que a criança ocupa nesta comunicação? Estes são questionamentos importantes para pensarmos a importância da linguagem oral para compreender o significado das palavras pelas crianças (bem como para que avancem na apropriação de um arcabouço cada vez maior de generalizações).

Ao apontar para a criança um lugar essencial na constituição da influência do meio sobre o desenvolvimento humano, Vigotski aponta para uma concepção de criança rica e possibilidades, capaz de estabelecer relações com o mundo que a rodeia e que, na escola infantil, deve contemplar experiências ricas e diversificadas com a cultura histórica e socialmente criada, diferente do que ocorre quando ao criança é compreendida como pobre de possibilidades - alguém que deve ser protegido e cuidado num ambiente de simulações superficiais e facilitadas da cultura que criam um mundo à parte para a infância, um mundo pobre de vivências com a cultura elaborada." (MELLO, 2010, p. 730)

Voltamos a reforçar que, isso significa encarar o bebê como sujeito (ativo!), que atribui sentido, valor ao que vivencia e não objeto (passivo) da aprendizagem. Nesta perspectiva, o professor é visto como parceiro de vivências, que cria mediações ao apresentar a cultura para a criança e. Para isso é preciso sensibilidade para enxergar as iniciativas de comunicação das crianças. Lísina (1987, p. 278) aponta quatro indicadores, por parte das crianças em suas manifestações, como elementos importante para que se estabeleça uma atividade comunicativa: "a atenção e o interesse [em relação] ao adulto; a matriz emocional com que [a criança] percebe a ação do adulto; os atos que a criança realiza por iniciativa própria e cujo objeto é o adulto e; a sensibilidade da criança para a atitude que o adulto manifesta em reação com as ações daqueles."

A regulação da conduta, por exemplo, se formará a partir das condições concretas que forem ofertadas para a criança. A atitude antecipadora do adulto, se direcionando para a criança enquanto sujeito ativo da interação, um processo compreendido como coparticipativo, modelará ativamente a nova conduta infantil, por meio da atenção, o olhar, da fala (e seu tom), da escuta sensível, das orientações (positivas) que favorecem o exercício do modelo adequado que se espera dela e não enfatizando apenas seus erros com repreensões (gritos) e castigos.

Dessa forma, para criar necessidades e motivos de comunicação é preciso pensar sobre o lugar que a criança ocupa nas relações sociais das quais participa. A mudança de atitude em relação a este lugar (ou não lugar), será crucial para fazer avançar seu desenvolvimento, pois conforme a criança vai estabelecendo relações, vai também formando uma autoimagem de si, uma valoração de si e das pessoas do seu entorno. E isso é fundamental para o desenvolvimento psíquico, pois a criança ainda não é capaz de regular a própria conduta e vai aprendendo por meio de um modelo mais experiente que colabora na formação de sua inteligência e personalidade. A segurança emocional, além de favorecer o desenvolvimento da autonomia, também desperta sentimentos de coletividade, tão fundamentais numa educação humanizadora.

Ao passo que confiamos mais nas crianças como sujeitos ativos e capazes, concebendo-as como os futuros dirigentes, vamos também confiando mais em nós, como intelectuais, assumindo-nos como pesquisadores, autores e militantes para criar uma nova cultura escolar que tenha por base a compreensão da complexidade do processo educativo e do desenvolvi- 
mento humano na infância que leva à formação da inteligência e personalidade. (MELLO, 2017c) Desta maneira, a comunicação se constitui como uma atividade essencial para o homem para se desenvolver, e, a linguagem oral, possibilita à criança a apropriação dos significados das palavras, e, com isso, ir gradativamente se apropriando das objetivações sócio históricas e culturais da humanidade de modo a formar suas funções psíquicas superiores.

\section{CONSIDERAÇÕES FINAIS}

Educação e desenvolvimento humano estão profundamente ligados na constituição das qualidades especificamente humanas - as funções psíquicas superiores - desde os primeiros dias de vida e são responsáveis pela formação e desenvolvimento da inteligência e da personalidade. Por isso, promover o desenvolvimento do bebê visando sua maior autonomia e segurança afetiva é um desafio que e requer a superação da dicotomia entre o educar e cuidar, compreendendo-os como uma unidade dialética, assim como a concepção de que a prática pedagógica é um trabalho coletivo, construído na inter-relação. A revolução no olhar docente começa a partir do momento em que sua consciência tem por base conhecimentos que lhe possibilitem ampliar ao invés de limitar as vivências dos pequenos, potencializar todos os espaços e tempos/momentos, considerando as necessidades individuais e estando atento aos sinais dos pequenos. A comunicação é um elemento chave nessa relação.

Na experiência Loczy, trabalha-se com a ideia de que para o bebê desenvolver sua atividade autônoma, é preciso que ele exista como sujeito. Então, o envolvimento individual é parte fundamental do processo, e o diálogo é ferramenta essencial. Entretanto, precisamos ter clareza de que a comunicação com o bebê não é construída a partir de ordens e repreensões acompanhadas de profundos silêncios nos momentos em que o adulto está com ele. A comunicação deve ser colaborativa, sensível às demandas do bebê, promotora da curiosidade, afetiva.

Conforme a criança vai compreendendo cada vez mais a fala dos adultos, a linguagem passa a cumprir uma função muito importante no seu desenvolvimento psíquico, na regulação da sua conduta. E isso se dá na relação com o adulto, na comunicação com ele, sob sua orientação atenta e antecipadora que, a partir dos momentos de cuidado (banho, sono, troca, alimentação) vai desenvolvendo processos de educação no olhar atento, na escuta, na resposta às suas necessidades, no tom da voz, no toque, no respeito ao seu corpo e sua individualidade, na singularização e identidade. Para isso, levamos a criança a conhecer o seu corpo, explorar movimentos, a se interessar por objetos e à explorá-los, incentivamos e valorizamos suas iniciativas de fala, assim como o seu direito ao ócio e ao silêncio, respeitando seu ritmo, e com isso, levando-a a ter autoconfiança e segurança afetiva e, com isso, uma relação de maior independência no ambiente e no mundo.

A influência do meio no desenvolvimento é diferente para cada sujeito, vai depender da relação que cada criança estabelece com o meio, ou seja, da afetação produzida nessa relação e em relações anteriores - suas vivências. O meio pode ser organizado para ampliar as possibilidades de ação das crianças afetando-as positivamente, para aguçá-las, para despertar necessidades de agir, enriquecendo suas possibilidades de desenvolvimento. Para isso, é preciso que o professor se questione constantemente: quais concepções de ser humano, de mundo, de criança, de desenvolvimento, de educação guiam minha prática pedagógica? Que tipo de 
intencionalidade carrega? Me assumo como intelectual de minha prática? Assumo como um trabalho solitário/cansativo e prescritivo (quase sempre autoritário) ou construo uma relação colaborativa e por isso, dialógica com os pequenos, com os outros adultos da escola e com as famílias?

A qualidade da comunicação é um elemento essencial para que o bebê possa se desenvolver de forma positiva e segura por que, por meio dela, é visto, ouvido e atendido em suas necessidades e isso também significa encantá-las, criando novas necessidades e afetos na forma como apresentamos o mundo à elas. Mas para isso, o professor precisa concebê-lo como um ser ativo (sempre!), um parceiro da relação num trabalho colaborativo que cria as máximas possibilidades para o seu desenvolvimento psíquico, motor, afetivo e volitivo. E isso demanda sensibilidade, disposição e compromisso para com o outro, assim como assumir-se como um intelectual de sua prática. Isso é revolucionário e humanizador, principalmente em tempos de bárbarie.

ABSTRACT: We were born with a single capacity, that of learning and, with that, developing. However, we need to be in concrete conditions favorable to life and education. Communication will play an essential role in this process. In this text we aim to reflect on the role of communication in early childhood education, from the theoretical assumptions of Historical-Cultural Theory, aiming to dialogue with teachers about the importance of talking to babies, establishing a relationship and provoking new needs in them, including speaking, leading to the gradual development of his psychic functions (perception, memory, attention, language) so that he is able to interpret and understand the world around him in an increasingly conscious and sophisticated way. As a result, it seeks as a result to contribute to the advancement in the discussions of Pedagogy of Childhood, as well as to provide theoretical and methodological subsidies for an intentional, grounded and humanizing pedagogical practice.

KEYWORDS: Historical-Cultural Theory. Child education. Communication. Baby.

\section{REFERÊNCIAS}

CHEROGLU, S.; MAGALHÃES, S. M. O primeiro ano de vida: vida uterina, transição pós-natal e atividade de comunicação emocional direta com o adulto. In: MARTINS, L. M.; ABRANTES, A. A.; FACCI, M. G. D. Periodização Histórico-Cultural do Desenvolvimento Psíquico: do nascimento à velhice. Campinas-SP: Autores Associados, 2016.

DAVYDOV, V. V. La enseñanza escolar y el desarrollo psíquico. Moscú: Editorial Progreso, 1988.

GRAMSCI, A. Cadernos do Cárcere Vol 2. Os intelectuais. O princípio educativo. Jornalismo. Edição e tradução: Carlos Nelson Coutinho; co-edição: Luiz Sérgio Henriques e Marco Aurélio Nogueira. 2 ed. Rio de Janeiro: Civilização Brasileira, 2004.

LAZARETTI, L. M.; ARRAIS, L. F. L. O que cabe no currículo da educação infantil? Um convite à reflexão. In: EDUC. ANÁL., LONDRINA, V.3, N.2, P.27-46, JUL./DEZ. 2018 Disponível em: http://www.uel.br/seer/index.php/educanalise/article/viewFile/33682/25300

Acesso em: 14/04/2020

LEONTIEV, A. N. Uma contribuição à teoria do desenvolvimento da psique infantil. In: VIGOTISKII, LURIA e LEONTIEV. Linguagem, desenvolvimento e aprendizagem. São Paulo: Ícone editora, 2001.

LIMA, E. A. Infância e teoria histórico-cultural: (des) encontros da teoria e da prática. Tese de Doutorado. Faculdade de Filosofia e Ciências da Universidade Estadual Paulista Júlio de Mesquita Filho, Campus de Marília, 2005.

LÍSINA, M. La génesis de las formas de la comunicación en los niños. In : DAVÍDOV, V., SHUARE, M. (Orgs.). La Psicología Evolutiva y Pedagógica en la URSS (Antología). Moscou: Editorial Progresso, 1987. p. 274 - 298.

MAGALHÃES, G. M. Atividade-guia e neoformações psíquicas: contribuições da Psicologia 
Histórico-Cultural para o ensino desenvolvente na Educação Infantil. In: Crítica Educativa (Sorocaba/SP), v. 4, n. 2, p. 275-286, jul./dez.2018 Disponível em: http://www.criticaeducativa. ufscar.br/index.php/criticaeducativa/article/view/354

Acesso em: 15/07/2019

MELLO, S. A. A escuta como método nas relações na escola da infância. In: COSTA, S. A.; MELLO, S. A. (orgs.). Teoria Histórico-Cultural na Educação Infantil: conversando com professoras e professores. Curitiba: CRV, 2017c.

MELLO, S. A. Bebês e crianças pequenininhas como sujeitos: participação e escuta. In: COSTA, S. A.; MELLO, S. A. (orgs.). Teoria Histórico-Cultural na Educação Infantil: conversando com professoras e professores. Curitiba: CRV, 2017b.

MELLO, S. A. O cuidado e a educação de bebês e a formação de dirigentes. In: Nuances: estudos sobre Educação, Presidente Prudente-SP, v. 28, n. 3, p. 23-42, Set/Dez, 2017a Disponível em: http:// revista.fct.unesp.br/index.php/Nuances/article/view/5273

Acesso em: 28/06/2019

A questão do meio na pedologia e suas implicações pedagógicas. In: Psicol. USP [online]. 2010, vol.21, n.4, pp.727-739. Disponível em: http://www.scielo.br/scielo.php?pid=S0103$65642010000400005 \&$ script $=$ sci_abstract\&tlng $=$ pt

Acesso em: 14/05/2019

SILVA, J. R. Contribuições da teoria histórico-cultural para a compreensão do bebê como sujeito ativo. In: SILVA, J. R.; SOUZA, R. A. M.; MELLO, S. A.; LIMA, V. G. (Orgs.). Educação de Bebês: cuidar e educar para o desenvolvimento humano. São Carlos-SP: Pedro \& João Editores, 2018.

VIGOTSKI, L. S. Sete aulas de L. S. Vigotski sobre os fundamentos da pedologia. Trad. Zoia Prestes, Elizabeth Tunes, Cláudia da Costa Guimarães Santana. Rio de Janeiro: E-Papers, 2018.

VYGOTSKI, L. S. Obras escogidas IV. Madrid: Machado Grupo de Distribución, 2012. VOLÓCHINOV, V. Marxismo e filosofia da linguagem: problemas fundamentais do método sociológico na ciência da linguagem. 2 ed. Trad. Sheila Grillo, Ekaterina Vólkova Américo. São Paulo: Editora 34, 2018.

ZAPOROZET, A. V.; LISINA, M. I. (Orgs.). El desarrollo de la comunicación en la infancia. Madri: G. Núñez Editor, 1986.

Data submissão: 19/06/2020

Data aprovação:21/06/2020 